\title{
Emotional Intelligence and Will to Win among Male Hockey Players
}

\author{
Baljinder Singh Bal ${ }^{1 *}$, Sanjeev Mundair ${ }^{2}$, Davinder Singh ${ }^{1}$ \\ ${ }^{1}$ Department of Physical Education (T), Guru Nanak Dev University, Amritsar, India \\ ${ }^{2}$ Lakshmibai National Institute of Physical Education, North East Regional Centre, Guwahati, India \\ Email: ${ }^{\text {bal baljindersingh@yahoo.co.in }}$
}

Received 12 June 2014; revised 16 July 2014; accepted 30 July 2014

Copyright @ 2014 by authors and Scientific Research Publishing Inc.

This work is licensed under the Creative Commons Attribution International License (CC BY).

http://creativecommons.org/licenses/by/4.0/

(c) (i) Open Access

\section{Abstract}

This study examined the emotional intelligence and will to win level among male hockey players. To obtain data, the investigators had selected Ninety $(N=90)$ male Hockey players of 19 to 25 years of age to act as subjects. They were divided into three groups: (i.e., $N_{1}=30$; Defenders, $N_{2}=$ 30; Midfielders and $N_{3}=30$ Attackers). The purposive sampling technique was used to select the subjects. All the subjects, after having been informed about the objective and protocol of the study, gave their consent and volunteered to participate in this study. To measure the level of emotional intelligence of the subjects, the emotional intelligence scale constructed by Hyde et al. (2001) was administered. To measure the level of will to win was measured by applying will to win questionnaire prepared by Kumar and Shukla (1998). One Way Analysis of Variance (ANOVA) was employed to compare the different playing positions in hockey. Where " $F$ " values were found significant, LSD (Least Significant Difference) post-hoc test was applied to find out the direction and degree of difference. For testing the hypotheses, the level of significance was set at 0.05 . The results revealed significant difference with regard to the sub-variables self-awareness of emotional intelligence among male hockey players from different playing positions. However, No significant differences were found on the sub-variables: Empathy, self-motivation, emotional stability, managing relations, integrity, self-development, value orientation, commitment and altruistic behaviour. The results revealed significant difference with regard to variable will to win among male hockey players from different playing positions. The Midfielders players have higher levels of will to win as compared to their counterpart Defenders and Attackers.

\section{Keywords}

Emotional Intelligence, Will to Win, Defenders, Midfielders and Attackers

\footnotetext{
${ }^{*}$ Corresponding author.
} 


\section{Introduction}

Sports and games are competitive in nature and are meant for a specific age group. The participation is only enjoyed by the talented and gifted youngsters. Hockey is a sport requiring high level of fitness. Hockey players need a good combination of physical, physiological as well as psychological fitness in order to succeed. Of all the factors affecting sports performance, it seems that the most important one is the ability of the athlete to identify and assume the appropriate feeling required to perform at his best when he needs to do. Whatever might be the level of skill, strength and experience of an athlete, his performance in the face of stiff competition will be largely influenced by his ability to assume the right emotion and attain an appropriate level of the emotional energy for performing at his optimum. According to Kauss (1996), how you feel is how you will play. The significance of emotional influence on sport performance has often been evident in most comments of spectators, team managers and sports analysts on athletes' and teams' performances during and after competitions. Often times, they comment on players' display of confidence or lack of it, aggressiveness or timidity, resilience or depression, anger or enthusiasm, frustration or determination and other forms of emotionality while attributing to such factors, the responsibility for the success or failure of their performances. The implication is that preparation of athletes for successful performance in major competitions can no longer be predicated only on training them for optimum mental qualities and physical qualities as strength, speed, flexibility and skills but also perhaps more importantly, on training for development of adequate emotional intelligence, which will make possible a successful delivery of all the trainings acquired.

Emotional intelligence is “the ability to monitor one's own and other's emotions, to discriminate among them, and to use the information to guide one’s thinking and actions” (Salovey \& Mayer, 1990: p. 198). Salovey and Mayer (1990) introduced the "ability model” that includes four major themes of abilities included in emotional intelligence, namely 1) perceiving emotions, 2) using emotions, 3) understanding emotions, and 4) managing emotions. The mastery of these four major dimensions of emotional learning is referred to as emotional intelligence. While Salovey and Mayer may have initiated the conceptual development of emotional intelligence, Daniel Goleman is given credit for popularizing. Goleman believed that in addition to cognitive intelligence, individuals are also equipped with emotional intelligence. Children and youth may be able to learn and refine these emotional abilities through sport participation.

Mayer, Salovey, \& Caruso (2004) described emotional intelligence as the subset of social intelligence that involves the ability to monitor one's own and others' feelings and emotions, to discriminate among them and to use this information to guide one's thinking and actions. They further emphasized that emotional intelligence involves the ability to reason with and about emotions, and the capacity of emotion to enhance thought. Hein (2006) described emotional intelligence as knowing how to separate healthy feelings from unhealthy ones and how to turn negative feelings into positive ones. Goleman (1999) asserted that it means managing feelings so that they are expressed appropriately and effectively, enabling people to work together smoothly towards their common goals. However, reports of application of emotional intelligence to amateur athletes and sports performances remain scanty. This study therefore investigated the applicability of emotional intelligence to male Hockey players and further administered a programme of emotional intelligence on the athletes with a view to establishing its effectiveness or otherwise on their sports.

This study therefore investigated the applicability of emotional intelligence to male Hockey players of different levels. Limited research has studied emotional intelligence and will to win. It seems intuitive that the level of one's emotional intelligence and will to win will relate to their performance and behavior on the sports field. Research has shown psychological skills facilitate athletic performance. Relaxation training, positive thought control, self-regulation, imagery, concentration, energy control, self-monitoring, and goal setting are all traits that have been correlated with athletic performance (Zizzi, Deaner, \& Hirschhorn, 2003). Many of these traits reflect emotional intelligence. These same traits have been correlated with work group cohesion, job performance, role conflict, and job satisfaction (Zizzi, Deaner, \& Hirschhorn, 2003). It seems intuitive that traits correlated with job behavior and performance also transfers to sports behavior and performance. Hanin (2006) concluded that each athlete must learn their own ideal psychological performance state where they are most successful. To do this, they must develop skills to recognize and manage their emotions. These two skills are two of the four branches measured by the ability model of emotional intelligence. It is intuitive that successful athletes who are able to reach their own individual performance state will exhibit high emotional intelligence. A major component of team sports is communicating with teammates and coaches, and working together towards a 
common goal. This happens when team members are aware of the feelings and emotions of themselves and others (Zizzi, Deaner, Hirschhorn, 2003). One of the few examining the relationship between sports and emotional intelligence studied National Hockey League players’ performances.

Paul (1960) rightly remarked "A winner never quits and the quitters never win". That means if one has the desire to win surely wins. It indicates that where there is a will, there is a way. It is expressed by scientist that the ability to work to the capacity is directly related to will to win. The psychological build-up is known to create a state of readiness. The main thrust of the modern sports is on winning, not just participating and playing. Physical Health and fitness or joy and fun are no longer the purpose or even the target. The dismissal performance of Indian players and athletes in international events has been largely attributed to the lack of will to win. It is the factor that makes great competitors. There are instances of men lacking physical qualification of great boxers still they have won. Will to win is the intensity to desire to defeat an opponent or to excel some performance standard in a given sports. This construct is similar to need-achievement and internal locus of control. It is also related partly to competition and some parts of aggression. The present study aimed to determine the difference in emotional intelligence and will to win in male Hockey players.

\section{Methods}

\subsection{Subjects}

To obtain data, the investigators had selected Ninety $(\mathrm{N}=90)$ male Hockey players of 19 to 25 years of age to act as subjects. They were divided into three groups: (i.e., $\mathrm{N}_{1}=30$; Defenders, $\mathrm{N}_{2}=30$; Midfielders and $\mathrm{N}_{3}=30$ Attackers). The purposive sampling technique was used to select the subjects. All the subjects, after having been informed about the objective and protocol of the study, gave their consent and volunteered to participate in this study.

\subsection{Selection of Variables}

With the above criteria's in mind, the psychological variable namely emotional intelligence and will to win were taken up for the present study:

1) Emotional intelligence.

- Self-awareness

- Empathy

- Self-motivation

- Emotional stability

- Managing relations

- Integrity

- Self-development

- Value orientation

- Commitment

- Altruistic behaviour

2) Will to win.

\subsection{Tools}

1) To measure the level of emotional intelligence of the subjects, the emotional intelligence scale constructed by Hyde et al. (2001) was administered.

2) To measure the level of will to win was measured by applying will to win questionnaire prepared by Kumar and Shukla (1998).

\subsection{Description of the Tests}

In order to measure the level of emotional intelligence and will to win of the subjects, two tools (i.e., questionnaires) have been used in this study. These tests have been described below:

\subsubsection{Emotional Intelligence}

This scale is a standardized tool which has already been used in many research/psychological investigations. 
After consulting relevant literature, 106 items were developed each item was transferred on a card. A panel of 50 judges with postgraduate degree and more than 10 years of experience in their relevant field was prepared. The items, which were chosen $75 \%$ or more times, were spotted out. The 34 items thus chosen were administered on 200 executives. The data was then tabulated and item total correlations were calculated, items having correlation less than the value of $0.25(P<0.01)$ were dropped. The final form of the scale constituted 34 items.

\subsubsection{Reliability}

The Reliability of the scale was determined by calculating reliability coefficient on a sample of 200 subjects. The split-half reliability coefficient was found to be 0.88 .

\subsubsection{Validity}

All items were related to the variable under focus, the scale has high content validly. It is evident from the assessment of judges/experts that items of the scale are directly related to the concept of emotional intelligence. In order to find out the validity from the coefficient of reliability and indicated high validity on account of being 0.93 .

\subsubsection{Factors of Emotional Intelligence}

The scale was administered on 200 executives and the scores obtained were subjected to factor analysis and ten factors were identified. These are self-awareness, empathy, self-motivation, emotional stability, managing relations, integrity, self-development, value orientation, commitment and altruistic behaviour.

1) Self-awareness: Self-awareness is being aware of one self and is measured by item 6, 12, 18, 29. These items are "I can continue to do what I believe in, even under severe criticism", "I have my priorities clear", "I believe in myself" and "I have built rapport and made maintained personal friendships with work associates".

2) Empathy: Empathy is feeling and understanding the other person and is measured by items 9, 10, 15, 20 and 25. These are "I pay attention to the worries and concerns of others", "I can listen to someone without the urge to say something", "I try to see the other person's point of view", "I am able to be focused even under pressure" and "I am able to handle multiple demands". These factors explain 7.3 percent variance with a total factor load of 3.11. The correlation of the factor with total score is 0.70 .

3) Self-motivation: Self-motivation is being motivated internally and is measured by 2, 4, 7, 8, 31 and 34. These items are "People tell me that I am an inspiration for them", "I am able to make intelligent decisions using a healthy balance of emotions and reason". "I am able to assess the situation and then behave". "I can concentrate on the task at hand in spite of disturbances", "I think that feelings should be managed" and "I believe that happiness is positive attitude". The factors accounts for 6.3 percent variance and a total factor load of are 3.28. Its correlation with total score is 0.77 .

4) Emotional stability: Emotional stability is measured by items 14, 19, 26 and 28. These are "I do not mix unnecessary emotions with issues at hand", "I am able to stay composed in both good and bad situations", "I am comfortable and open to novel ideas and new information" and "I am persistent in pursuing goals despite obstacles and setbacks". The factors explain 6.0 percent variance with a total factor load is 2.51 . The correlation of this factor with total score is 0.75 .

5) Managing relations: Managing relations is measured by 1, 5, 11 and 17. The statements that measure this factor are "I can encourage others to work even when things are not favorable", "I do not depend on others encouragement to do my work well", "I am perceived as friendly and outgoing" and "I can see the brighter side of my situations”. These factors explain 5.3 percent variance with a total factor load of 2.28. The correlation of this factor with total score is 0.67 .

6) Integrity: Integrity is measured by items 16, 27 and 32, "I can stand up for my beliefs", and "I pursue goals beyond what is required for me and I am aware of my weaknesses" are the statements that measure these factors. These factors explain 4.6 percent variance with a total factor load of 1.88 .

7) Self-development: Self-development is measured by items 30 and 33 which are "I am able to identify and separate my emotions" and "I feel that I must develop myself even when my job does not demand it" and explain 4.1 percent variance with a total factor load of 1.37.

8) Value orientation: Value orientation is measured by items 21, 22. The statements are "I am able to maintain the standards of honesty and integrity" and "I am able to confront unethical actions of others" and explain 4.1 percent variance with a total factor load of 1.29. 
9) Commitment: Commitment is measured by the items 23 and 24. "I am able to meet commitments and keep promises" and "I am organized and careful in my work" measure this factor. This factor accounts for 3.6 percent with a total factor load 1.39 .

10) Altruistic behaviour: Altruistic behaviour is measured by the items 3 and 13. The items are "I am able to encourage people to take initiatives" and "I can handle conflicts around me". It explains 3.0 percent variance with a total factor load of 1.3 .

\subsection{Will to Win}

Will to win questionnaire has immediate relevance in understanding the athlete's performance. This questionnaire may be successfully used by physical educators, trainers, coaches and sport psychologists as a screening device to identify the individual's performance in a sport activity.

\subsection{Reliability}

Hindi version of will to win questionnaire was administration on randomly selected sample of 200 subjects from competitive sports (100 makes and 100 males). The age range of subjects was 19 to 31 years with a mean age of the subjects was 19 to 31 years with a mean age of 24.86 years. In order to obtain test-retest reliability, it was re-administrated to the same groups after an interval of 6 weeks.

\subsection{Validity}

Several attempts were also made by Pezer and Brown (1980) to obtain validity data: 1) members of the university of Saskatchewan inter collegiate women's basketball team $(\mathrm{N}=10)$ completed with the description of will to win, assessed each players will to win on a ten-point scale (Nunally, 1967). The correlation between will to win scores and the coach's assessment was 0.78 ; 2$)$. A senior women's basketball team $(\mathrm{N}=10)$, which completed locally and ultimately nationally, completed the will to win questionnaire. After they had completed the will to win, players were rated by teammates on the same ten-point scale. The correlation between teammate's evaluation and will to win was 0.72 ; 3) twenty four women curlers, representing six universities competing in the Canada west inter collegiate curling championships, completed the will to win questionnaire. Following the same procedure used in the basketball studies, mean team assessment correlated 0.72 with actual will to win.

\section{Statistical Analysis}

One Way Analysis of Variance (ANOVA) was employed to compare the different playing positions in hockey. Where "F" values were found significant, LSD (Least Significant Difference) post-hoc test was applied to find out the direction and degree of difference. For testing the hypotheses, the level of significance was set at 0.05 .

\section{Results}

Table 1 presents significant differences with regard to the sub-parameter self-awareness among Defenders, Midfielders and Attackers male Hockey players as the $P$-value (Sig.) 0.005 was found smaller than the 0.05 level of significance $(P<0.05)$. Since the obtained F-value was found significant, therefore, Least Significant Difference (LSD) post-hoc test was employed to study the direction and significance of differences between paired means among various playing positions of male Hockey players on the sub-parameter self-awareness. The results of LSD post-hoc test have been presented in Table 2.

A glance at Table 2 showed that the mean value of Defenders players was 16.16 whereas Midfielders players had mean value as 14.50 and the mean difference between both the groups was found 1.66 . The $P$-value sig 0.024 shows that the Defenders players had demonstrated significantly better on self-awareness than their counterpart's Midfielders players. The mean difference between Defenders and Attackers players was found 0.70. The $P$-value (Sig.) 0.337 showed that Defenders player had exhibited better self-awareness though not significantly than their counterpart Attackers players. The mean difference between Midfielders and Attackers players was found 2.36. The $P$-value sig 0.002 shows that the Defenders players had demonstrated significantly better on self-awareness than their counterpart's Midfielders players. The graphical representation of responses has been exhibited in (Figure 1). 
Table 1. Analysis of variance (ANOVA) results among Defenders, Midfielders and Attackers male hockey players with regard to the sub-parameter self-awareness.

\begin{tabular}{cccccc}
\hline Source of variance & Sum of Squares & df & Mean Square & F-Ratio & $P$-Value Sig. \\
\hline Between Groups & 88.689 & 2 & 44.344 & & \\
Within Groups & 685.133 & 87 & 7.875 & 5.631 & 0.005 \\
Total & 773.822 & 89 & & & \\
\hline
\end{tabular}

*Significant at 0.05. $\mathrm{F}_{0.05}(2,87)$.

Table 2. Analysis of least significant difference (LSD) post-hoc test among Defenders, Midfielders and Attackers male hockey players with regard to the sub-parameter self-awareness.

\begin{tabular}{cccc}
\hline Group (A) & Group (B) & Mean Difference (A-B) & $P$-Value (Sig.) \\
\hline \multirow{2}{*}{ Defenders (Mean = 16.16) } & Midfielders & $1.66667^{*}$ & 0.024 \\
& Attackers & -0.70000 & 0.337 \\
Midfielders (Mean = 14.50) & Defenders & $-1.66667^{*}$ & 0.024 \\
& Attackers & $-2.36667^{*}$ & 0.002 \\
Attackers (Mean = 16.86) & Defenders & 0.70000 & 0.337 \\
& Midfielders & $2.36667^{*}$ & 0.002 \\
\hline
\end{tabular}

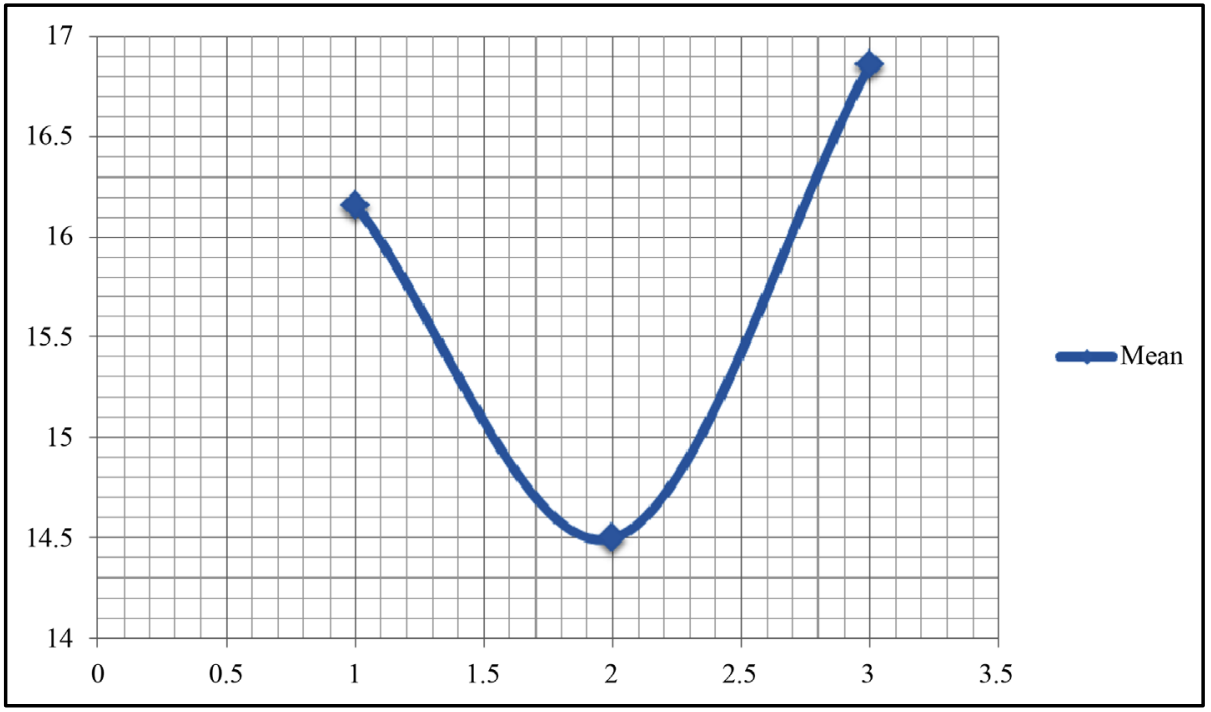

Figure 1. Graphical representation of mean scores with regard to Defenders, Midfielders and Attackers male hockey players on the sub-parameter self-awareness.

It is evident from Table 3 that insignificant differences have been found with regard to the sub-parameter empathy among Defenders, Midfielders and Attackers male Hockey players as the $P$-value (Sig.) 0.298 was found higher than the 0.05 level of significance $(P>0.05)$. Since F-value was found insignificant, therefore, there is no need to apply post-hoc test.

It can be observed from Table 4 that insignificant differences have been found with regard to the sub-parameter self-motivation among Defenders, Midfielders and Attackers male Hockey players as the $P$-value (Sig.) 0.386 was found higher than the 0.05 level of significance $(P>0.05)$. Since $F$-value was found insignificant, therefore, there is no need to apply post-hoc test.

The results depicted in Table 5 that insignificant differences have been found with regard to the sub-parameter emotional stability among Defenders, Midfielders and Attackers male Hockey players as the $P$-value (Sig.) 0.269 was found higher than the 0.05 level of significance $(P>0.05)$. Since F-value was found insignificant, 
therefore, there is no need to apply post-hoc test.

It has been observed from Table 6 that insignificant differences have been found with regard to the sub-parameter managing relations among Defenders, Midfielders and Attackers male Hockey players as the $P$-value (Sig.) 0.092 was found higher than the 0.05 level of significance $(P>0.05)$. Since F-value was found insignificant, therefore, there is no need to apply post-hoc test.

It has been observed from Table 7 that insignificant differences have been found with regard to the sub-parameter managing relations among Defenders, Midfielders and Attackers male Hockey players as the $P$-value

Table 3. Analysis of variance (ANOVA) results among Defenders, Midfielders and Attackers male hockey players with regard to the sub-parameter empathy.

\begin{tabular}{cccccc}
\hline Source of variance & Sum of Squares & df & Mean Square & F-Ratio & $P$-Value Sig. \\
\hline Between Groups & 27.222 & 2 & 13.611 & & 0.298 \\
Within Groups & 964.600 & 87 & 11.087 & & \\
Total & 991.822 & 89 & & & \\
\hline
\end{tabular}

*Significant at 0.05. $\mathrm{F}_{0.05}(2,87)$.

Table 4. Analysis of variance (ANOVA) results among Defenders, Midfielders and Attackers male hockey players with regard to the sub-parameter self-motivation.

\begin{tabular}{cccccc}
\hline Source of Variance & Sum of Squares & df & Mean Square & F-Ratio & $P$-Value Sig. \\
\hline Between Groups & 16.467 & 2 & 8.233 & & 0.962 \\
Within Groups & 744.433 & 87 & 8.557 & & 0.386 \\
Total & 760.900 & 89 & & \\
\hline
\end{tabular}

*Significant at $0.05 . \mathrm{F}_{0.05}(2,87)$.

Table 5. Analysis of variance (ANOVA) results among Defenders, Midfielders and Attackers male hockey players with regard to the sub-parameter emotional stability.

\begin{tabular}{cccccc}
\hline Source of Variance & Sum of Squares & df & Mean Square & F-Ratio & $P$-Value Sig. \\
\hline Between Groups & 18.156 & 2 & 9.078 & & 0.269 \\
Within Groups & 592.300 & 87 & 6.808 & 1.333 & \\
Total & 610.456 & 89 & & & \\
\hline
\end{tabular}

*Significant at $0.05 . \mathrm{F}_{0.05}(2,87)$.

Table 6. Analysis of variance (ANOVA) results among Defenders, Midfielders and Attackers male hockey players with regard to the sub-parameter managing relations.

\begin{tabular}{cccccc}
\hline Source of Variance & Sum of Squares & df & Mean Square & F-Ratio & $P$-Value Sig. \\
\hline Between Groups & 21.356 & 2 & 10.678 & & \\
Within Groups & 378.300 & 87 & 4.348 & 2.456 & 0.092 \\
Total & 399.656 & 89 & & & \\
\hline
\end{tabular}

*Significant at $0.05 . \mathrm{F}_{0.05}(2,87)$.

Table 7. Analysis of variance (ANOVA) results among Defenders, Midfielders and Attackers male hockey players with regard to the sub-parameter integrity.

\begin{tabular}{cccccc}
\hline Source of Variance & Sum of Squares & df & Mean Square & F-Ratio & $P$-Value Sig. \\
\hline Between Groups & 10.289 & 2 & 5.144 & & \\
Within Groups & 248.200 & 87 & 2.853 & 1.803 & 0.171 \\
Total & 258.489 & 89 & & & \\
\hline
\end{tabular}

*Significant at $0.05 . \mathrm{F}_{0.05}(2,87)$. 
(Sig.) 0.171 was found higher than the 0.05 level of significance $(P>0.05)$. Since F-value was found insignificant, therefore, there is no need to apply post-hoc test.

It has been observed from Table 8 that insignificant differences have been found with regard to the sub-parameter self-development among Defenders, Midfielders and Attackers male Hockey players as the $P$-value (Sig.) 0.059 was found higher than the 0.05 level of significance $(P>0.05)$. Since F-value was found insignificant, therefore, there is no need to apply post-hoc test.

It has been observed from Table 9 that insignificant differences have been found with regard to the sub-parameter value orientation among Defenders, Midfielders and Attackers male Hockey players as the $P$-value (Sig.) 0.232 was found higher than the 0.05 level of significance $(P>0.05)$. Since F-value was found insignificant, therefore, there is no need to apply post-hoc test.

It has been observed from Table 10 that insignificant differences have been found with regard to the sub-parameter commitment among Defenders, Midfielders and Attackers male Hockey players as the $P$-value (Sig.) 0.088 was found higher than the 0.05 level of significance $(P>0.05)$. Since F-value was found insignificant, therefore, there is no need to apply post-hoc test.

It has been observed from Table 11 that insignificant differences have been found with regard to the sub-parameter altruistic behaviour among Defenders, Midfielders and Attackers male Hockey players as the P- value (Sig.) 0.129 was found higher than the 0.05 level of significance $(P>0.05)$. Since F-value was found in

Table 8. Analysis of variance (ANOVA) results among Defenders, Midfielders and Attackers male hockey players with regard to the sub-parameter self-development.

\begin{tabular}{cccccc}
\hline Source of Variance & Sum of Squares & df & Mean Square & F-Ratio & $P$-Value Sig. \\
\hline Between Groups & 17.489 & 2 & 8.744 & & \\
Within Groups & 259.800 & 87 & 2.986 & 0.059 \\
Total & 277.289 & 89 & & \\
\hline
\end{tabular}

*Significant at $0.05 . \mathrm{F}_{0.05}(2,87)$.

Table 9. Analysis of variance (ANOVA) results among Defenders, Midfielders and Attackers male hockey players with regard to the sub-parameter value orientation.

\begin{tabular}{|c|c|c|c|c|c|}
\hline Source of Variance & Sum of Squares & df & Mean Square & F-Ratio & $P$-Value Sig. \\
\hline Between Groups & 5.489 & 2 & 2.744 & & \\
\hline Within Groups & 160.567 & 87 & 1.846 & 1.487 & 0.232 \\
\hline Total & 166.056 & 89 & & & \\
\hline
\end{tabular}

*Significant at $0.05 . \mathrm{F}_{0.05}(2,87)$.

Table 10. Analysis of variance (ANOVA) results among Defenders, Midfielders and Attackers male hockey players with regard to the sub-parameter commitment.

\begin{tabular}{cccccc}
\hline Source of Variance & Sum of Squares & df & Mean Square & F-Ratio & $P$-Value Sig. \\
\hline Between Groups & 7.400 & 2 & 3.700 & & \\
Within Groups & 128.700 & 87 & 1.479 & 2.501 & 0.088 \\
Total & 136.100 & 89 & & \\
\hline
\end{tabular}

*Significant at $0.05 . \mathrm{F}_{0.05}(2,87)$.

Table 11. Analysis of variance (ANOVA) results among Defenders, Midfielders and Attackers male hockey players with regard to the sub-parameter altruistic behaviour.

\begin{tabular}{cccccc}
\hline Source of Variance & Sum of Squares & df & Mean Square & F-Ratio & $P$-Value Sig. \\
\hline Between Groups & 9.689 & 2 & 4.844 & & \\
Within Groups & 201.300 & 87 & 2.314 & 2.094 & 0.129 \\
Total & 210.989 & 89 & & & \\
\hline
\end{tabular}

*Significant at 0.05. $\mathrm{F}_{0.05}(2,87)$. 
significant, therefore, there is no need to apply post-hoc test.

It has been observed from Table 12 that insignificant differences have been found with regard to the parameter emotional intelligence among Defenders, Midfielders and Attackers male Hockey players as the $P$-value (Sig.) 0.371 was found higher than the 0.05 level of significance $(P>0.05)$. Since F-value was found insignificant, therefore, there is no need to apply post-hoc test.

Table 13 presents significant differences with regard to the parameter Will to Win among Defenders, Midfielders and Attackers male Hockey players as the $P$-value (Sig.) 0.017 was found smaller than the 0.05 level of significance $(P<0.05)$. Since the obtained F-value was found significant, therefore, Least Significant Difference (LSD) post-hoc test was employed to study the direction and significance of differences between paired means among various playing positions of male Hockey players on the parameter Will to Win. The results of LSD posthoc test have been presented in Table 14.

A glance at Table 14 showed that the mean value of Defenders players was 6.90 whereas Midfielders players had mean value as 8.50 and the mean difference between both the groups was found 1.60. The $P$-value (Sig.) 0.006 showed that Midfielders player had exhibited better will to win though not significantly than their counterpart Midfielders players. The mean difference between Defenders and Attackers players was found 1.16. The $P$-value (Sig.) 0.043 showed that Attackers player had exhibited better will to win though not significantly than their counterpart Defenders players. The mean difference between Midfielders and Attackers players was found 0.43. The $P$-value (Sig.) 0.447 showed that Midfielders player had exhibited better self-awareness though not significantly than their counterpart Attackers players. The graphical representation of responses has been exhibited in (Figure 2).

\section{Discussion of Results}

The present study has highlighted the significance of differences with regard to emotional intelligence; will to

Table 12. Analysis of variance (ANOVA) results among Defenders, Midfielders and Attackers male hockey players with regard to the parameter emotional intelligence.

\begin{tabular}{cccccc}
\hline Source of Variance & Sum of Squares & df & Mean Square & F-Ratio & $P$-Value Sig. \\
\hline Between Groups & 351.622 & 2 & 175.811 & & \\
Within Groups & 15257.533 & 87 & 175.374 & 1.002 & 0.371 \\
Total & 15609.156 & 89 & & & \\
\hline
\end{tabular}

*Significant at $0.05 . \mathrm{F}_{0.05}(2,87)$.

Table 13. Analysis of variance (ANOVA) results among Defenders, Midfielders and Attackers male hockey players with regard to the parameter will to win.

\begin{tabular}{cccccc}
\hline Source of Variance & Sum of Squares & df & Mean Square & F-Ratio & $P$-Value Sig. \\
\hline Between Groups & 41.089 & 2 & 20.544 & & 0.017 \\
Within Groups & 420.067 & 87 & 4.828 & 4.255 & \\
Total & 461.156 & 89 & & & \\
\hline
\end{tabular}

*Significant at $0.05 . \mathrm{F}_{0.05}(2,87)$.

Table 14. Analysis of least significant difference (LSD) post-hoc test among Defenders, Midfielders and Attackers male hockey players with regard to the parameter will to win.

\begin{tabular}{cccc}
\hline Group (A) & Group (B) & Mean Difference (A - B) & $P$-Value (Sig.) \\
\hline \multirow{2}{*}{ Defenders (Mean = 6.90) } & Midfielders & $-1.60000^{*}$ & 0.006 \\
& Attackers & $-1.16667^{*}$ & 0.043 \\
Midfielders (Mean = 8.50) & Defenders & $1.60000^{*}$ & 0.006 \\
& Attackers & 0.43333 & 0.447 \\
Attackers (Mean = 8.06) & Defenders & $1.16667^{*}$ & 0.043 \\
& Midfielders & -0.43333 & 0.447 \\
\hline
\end{tabular}




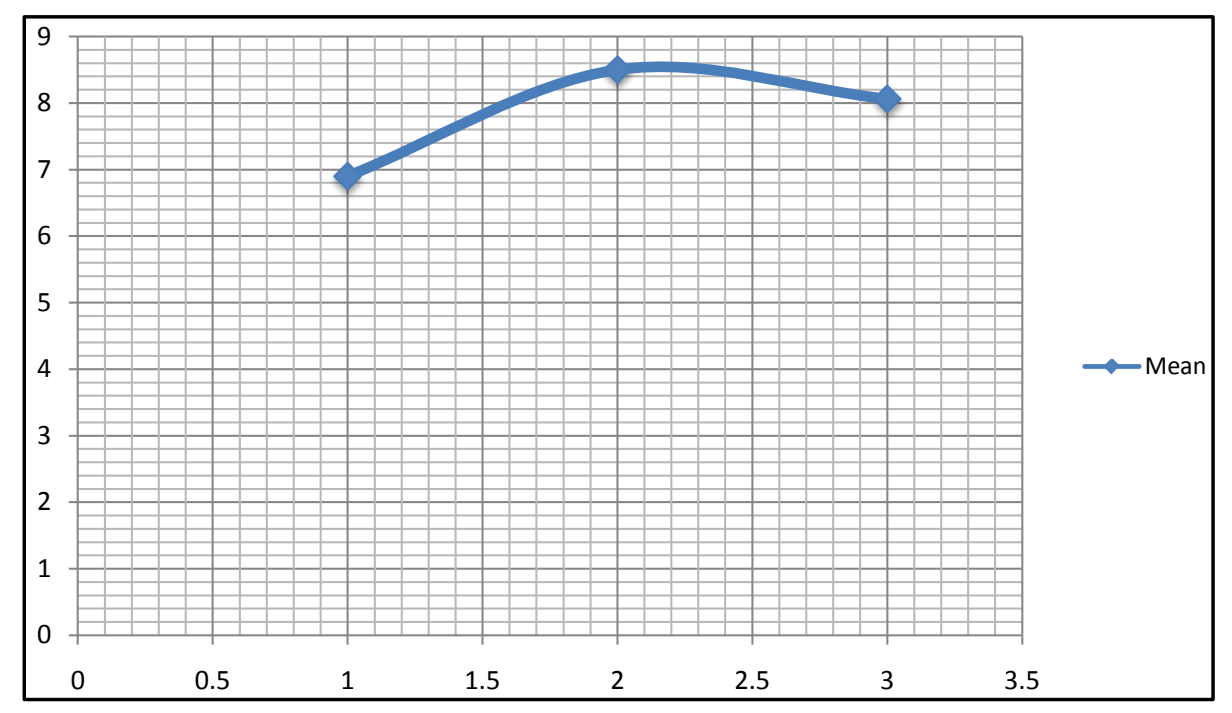

Figure 2. Graphical representation of mean scores with regard to Defenders, Midfielders and Attackers level male hockey players on the parameter will to win.

win, among male hockey players from different playing positions. A perusal at Analysis of Variance (ANOVA) Table 1 and Table 2 with regard to emotional intelligence of male hockey players revealed significant differences among different playing positions of hockey on the sub-variable of emotional intelligence i.e., self-awareness. While calculating the mean values of all the positions, it was observed that attacker male hockey players had demonstrated significantly better self-awareness as compared to their counterpart defenders and midfielders male hockey players. The outcome of results might be due to the fact that attacker male hockey players have the ability to understand and interpret one's own feelings and they continue to do what they believe in even under severe criticism. They have the clarity of their priorities, are able to build rapport and maintain personal friendships with their fellow players which enable them to outdo their opponents. Similar trends have been reported by Zamanian et al. (2011) revealed significantly higher self-awareness in athletes than non-athletes group.

Similarly, significant differences were found with regard to male hockey player's revealed significant differences among different playing positions on the variable i.e., will to win. While calculating the mean values of all the positions, it was observed that attacker male hockey players had demonstrated significantly will to win as compared to their counterpart defenders and midfielders male hockey players. It shows that attacker male hockey players are more determined to play well, pay more attention, show positive behaviour, demonstrate fighting spirit and believe more in deriving pleasure while playing which enabled them to outdo their counterpart defenders and midfielders male hockey players. Tiwari (2011) revealed significant relationship between will to win and locus of control of high \& low achiever rowers. Reddy et al. (2010) showed significant differences with regard to will to win among male long distance runners, short distance runners, jumpers and throwers. They further revealed that long distance runners were found to have significantly better will to win than short distance runners, jumpers and throwers.

\section{Conclusion}

The results revealed significant difference with regard to the sub-variables self-awareness of emotional intelligence among male hockey players from different playing positions. However, No significant differences were found on the sub-variables: Empathy, self-motivation, emotional stability, managing relations, integrity, selfdevelopment, value orientation, commitment and altruistic behaviour. The results revealed significant difference with regard to variable will to win among male hockey players from different playing positions. The Midfielders players have higher levels of will to win as compared to their counterpart Defenders and Attackers.

\section{Acknowledgements}

Authors would like to thank department of Physical Education and Sports (AT) Guru Nanak Dev University, 
Amritsar for providing assistance in collecting the relevant information for undertaking quality research. We would like to acknowledge the cooperation of athletes in data collection.

\section{References}

Goleman, D. (1999). The Human Task of a Project Leader. PM Network Journal, 13, 38-41.

Hyde, A., Pethe, S., \& Dhar, U. (2001). Publication Manual for Emotional Intelligence Scale. National Psychological Corporation, 4/230. Kacheri Ghat, Agra, India.

Kauss, D. R. (1996). Peak Performance: Mental Game Plans for Maximizing Your Athletic Potential. Englewood Cliffs, NJ: Prentice-Hall.

Kumar, A., \& Shukla, P. S. (1998). Psychological Consistencies within the Personality of High and Low Achieving Hockey Players. Paper Presented in the International Congress of Psychology, Montreal, Canada.

Mayer, J. D., Salovey, P., \& Caruso, D. R. (2004). Emotional Intelligence: Theory, Finding and Implication. Psycho Enquiry, 15, 197-215.

Paul, B. W. (1960). Building a Champion Football Teams. NJ: Englewood Cliffs

Pezer, V., \& Brown, M. (1980). Will to Win and Athletic Performance. International Journal of Sport Psychology, 11, 121-131.

Reddy, T. O., Singh, V., \& Reddy, T. P. (2010). Will to Win as a Psychological Differential to Play and Triumph among Female Runners, Jumpers and Throwers. British Journal of Sports Medicine, 44, i55.

Salovey, P., \& Mayer, J. D. (1990). Emotional Intelligence. Imagination, Cognition and Personality, 9, $185-211$.

Tiwari, L. M. (2011). Comparative Study of Will to Win and Locus of Control between High and Low Achievers of Rowing. Asian Journal of Physical Education and Computer Science in Sports, 4, 120-122.

Zamanian, F., Haghighi, M., Forouzandeh, E., Sedighi, Z., \& Salehian, M. H. (2011). A Comparison of Emotional Intelligence in Elite Student Athletes and Non-Athletes. Annals of Biological Research, 2, 179-183.

Zizzi, J. S., Deaner, H., \& Hirschhorn, D. (2003). The Relationship between Emotional Intelligence and Performance among College Baseball Players. Journal of Applied Sport Psychology, 15, 262-269. 
Scientific Research Publishing (SCIRP) is one of the largest Open Access journal publishers. It is currently publishing more than 200 open access, online, peer-reviewed journals covering a wide range of academic disciplines. SCIRP serves the worldwide academic communities and contributes to the progress and application of science with its publication.

Other selected journals from SCIRP are listed as below. Submit your manuscript to us via either submit@scirp.org or Online Submission Portal.
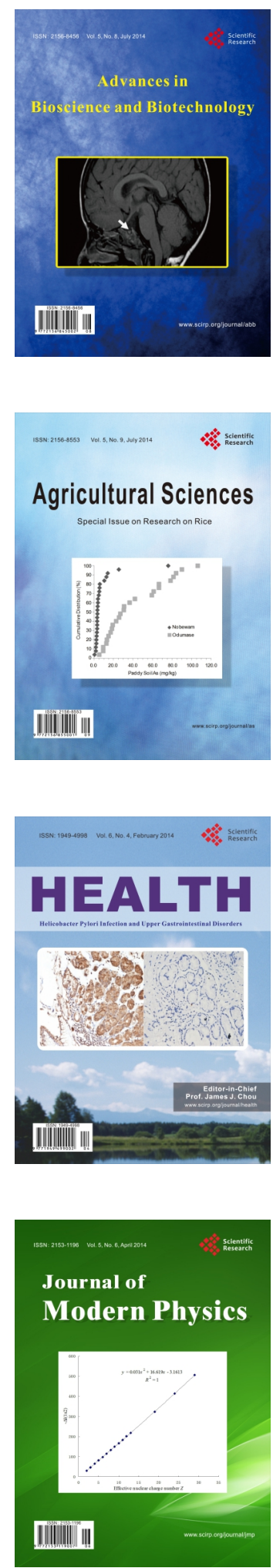
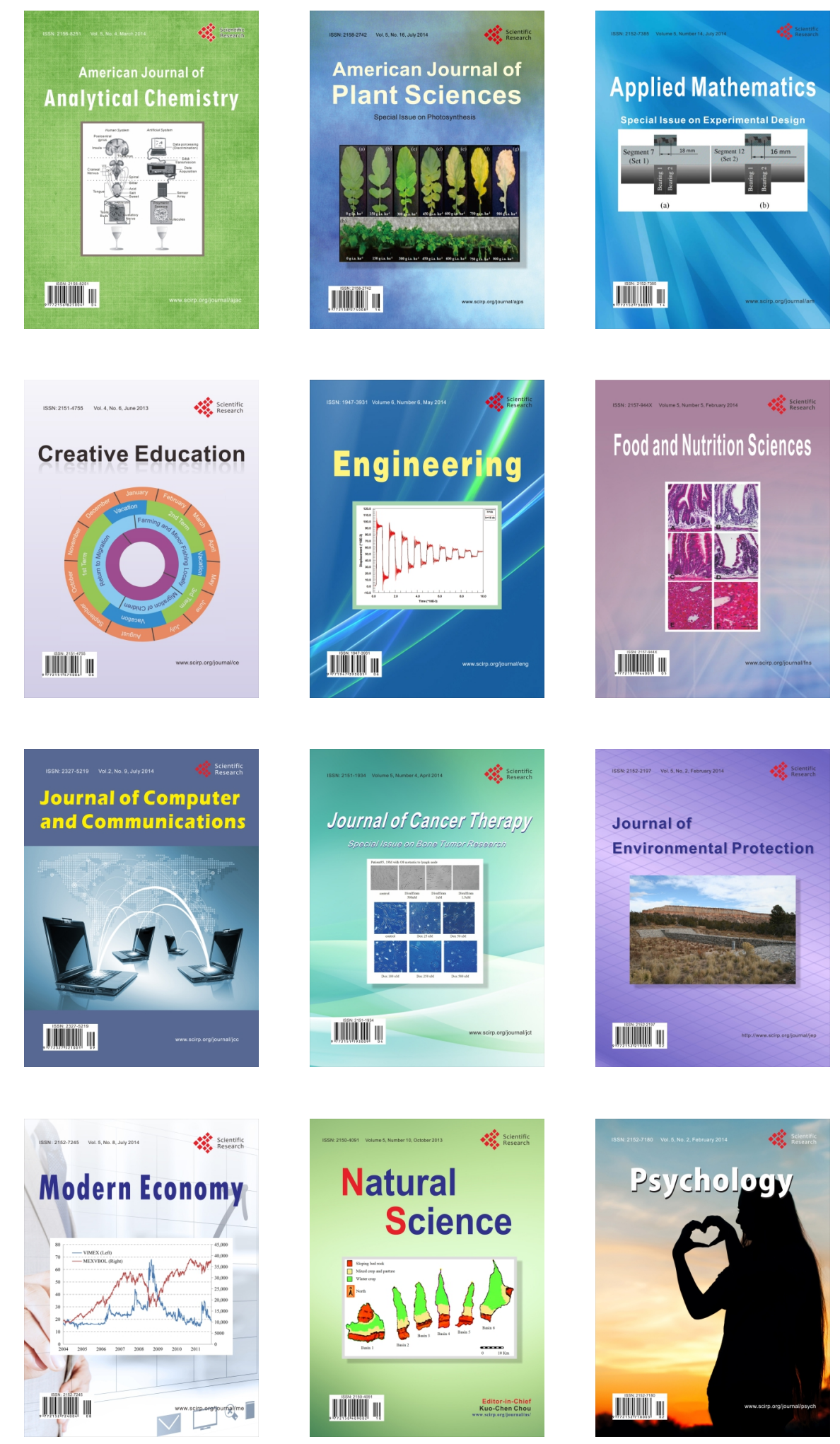